\title{
Discrete Terminal Super-Twisting Current Control of a Six-Phase Induction Motor
}

\author{
Yassine Kali $^{1}$ (D), Maarouf Saad ${ }^{1, *(\mathbb{D}}$, Jesus Doval-Gandoy ${ }^{2} \mathbb{D}$ and Jorge Rodas ${ }^{3}$ (D) \\ 1 Power Electronics and Industrial Control Research Group (GRÉPCI), École de Technologie Supérieure, \\ Montreal, QC H3C 1K3, Canada; yassine.kali.1@ens.etsmtl.ca \\ 2 Applied Power Electronics Technology Research Group (APET), Universidad de Vigo, Lagoas Marcosende \\ 36310 Vigo, Spain; jdoval@uvigo.es \\ 3 Laboratory of Power and Control Systems (LSPyC), Facultad de Ingeniería, Universidad Nacional de \\ Asunción, Luque 2060, Paraguay; jrodas@ing.una.py \\ * Correspondence: maarouf.saad@etsmtl.ca; Tel.: +1-514-396-8940
}

Citation: Kali, Y.; Saad, M.; Doval-Gandoy, J.; Rodas, J. Discrete Terminal Super-Twisting Current Control of a Six-Phase Induction Motor. Energies 2021, 14, 1339. https://doi.org/10.3390/en14051339

Academic Editor: Chunhua Liu

Received: 29 December 2020

Accepted: 25 February 2021

Published: 1 March 2021

Publisher's Note: MDPI stays neutral with regard to jurisdictional claims in published maps and institutional affiliations.

Copyright: (c) 2021 by the authors. Licensee MDPI, Basel, Switzerland. This article is an open access article distributed under the terms and conditions of the Creative Commons Attribution (CC BY) license (https:// creativecommons.org/licenses/by/ $4.0 /$ )

\begin{abstract}
In this manuscript, the high-accuracy stator currents tracking issue is considered for a sixphase induction motor subject to external perturbations and uncertainties due to unmeasurable rotor currents and electrical parameter variations. To achieve the control goals, the common two-cascade controllers structure is required for this type of motor. The first controller in the outer loop consists of a proportional integral to regulate the speed. Then, the second is the proposed inner nonlinear stator currents controller based on a robust discrete-time terminal super-twisting algorithm supported by the time-delay estimation method. For the design procedure, the discrete-time stator currents dynamics are derived; for example, the vector of the matched perturbations and unmeasurable rotor currents are specified to simplify the estimation. A detailed stability analysis of the closed-loop error dynamics using Lyapunov theory is given. Finally, a real asymmetrical six-phase induction motor is used to implement in real-time the developed method and to illustrate its effectiveness and robustness. The results obtained reveal a satisfactory stator currents tracking in steady state and transient conditions and under variation in the magnetizing inductance. Moreover, a comparative study with an existing method in steady state for two different rotor speeds is presented to show the superiority of the proposed discrete-time technique.
\end{abstract}

Keywords: discrete-time current control; Lyapunov; multiphase induction motor; super-twisting control; terminal sliding mode; field oriented control

\section{Introduction}

Nowadays, multiphase motor drives are extensively utilized in several real-life systems such as wind turbines [1], electric vehicles [2], ship propulsion system [3], and traction system for elevators [4] and others that have aroused a significant interest among the community of automation engineers and researchers to develop advanced nonlinear control techniques ensuring high-accurate stator currents tracking [5,6]. This interest belongs to the fact that these motors produce lower current/power per phase and lower torque ripple in comparison with well-known three-phase motors. In addition, multiphase motors are able to operate in faulty situations without the requirement of additional hardware [7]. However, the presence of uncertain parameters, unmeasured rotor currents, and matched perturbations make the control task complicated.

In the literature, earlier works considered similar methods applied to three-phase motors and proposed the extended version of the Proportional-Integral (PI) regulator [8], direct torque control [9], model predictive control [10,11], and others. Recently, advanced digital platforms encouraged the researchers to apply advanced intelligent and nonlinear control techniques such as fuzzy logic [12,13], nonlinear backstepping [14,15], Sliding Mode (SM) control [16-18], and others. 
Among the abovementioned methods, SM control is simply designed and is considered the most effective due to its good features that can be resumed by the following points [19]:

- insensitivity to a wide class of matched uncertainties and disturbances, and

- finite-time convergence of the commanded system trajectories to the selected sliding functions.

SM ensures these two features by using discontinuous input signals. However, this discontinuity limits SM's real-time implementation since it generates high-frequency switching signals that are the famous chattering phenomenon [20]. Therefore, this undesirable phenomenon can easily have irreversible damages on controlled-system actuators. Therefore, to reduce the extent of the chattering problem, discretized versions of the SM based on reaching law have been proposed [21-23]. Through several numerical simulations and experimental work, it has been concluded that the SM phase is no longer maintained even if the finite-time convergence to the sliding function is maintained, which introduced Discrete-time Quasi SM (DQSM) control [24]. In this method, the system trajectories converge to a band in the vicinity of the designed sliding function, where the bandwidth depends on the used reaching law.

To enhance the DQSM performance and to reduce the Quasi Sliding Mode Band (QSMB), a combination of the Time-Delay Estimation (TDE) method with DQSM based on exponential reaching law has been proposed for an asymmetrical six-phase Induction Motor (IM) [18]. This method aims to reproduce approximated signals to unmeasurable rotor currents and matched uncertainties and perturbations based on time-delayed computed voltages and measured states to minimize the choice of switching gains. However, a dilemma arose: small switching gains reduce chattering but deteriorate the tracking performance while large switching gains increase simultaneously the chattering level and the tracking accuracy but degrade the quality of electric energy (i.e., total harmonic distortion becomes high). This dilemma has been revealed through experimental works on a real six-phase IM using Gao's reaching law and exponential reaching law $[17,18]$.

As a solution, a TDE-based discrete-time super-twisting controller has been developed and implemented on the same asymmetrical six-phase IM [25]. The proposed method allows for higher precision while reducing chattering and improves electric energy quality. In this work, an attempt is made to enhance the results obtained using the abovementioned discrete-time second-order SM technique. The contributions of this work are summarized as follows:

- A terminal sliding function that is a nonlinear one instead of the conventional linear sliding function in [17] is introduced. Consequently, a faster convergence is obtained during the reaching phase.

- The matched external perturbations, unmodeled dynamics due to the unmeasurable rotor currents, and electrical parameters' variations are approximated using the TDE method. This latter is simple and easy to implement since it requires delayed determinate voltages, and actual and delayed existing measured stator currents.

- The estimated perturbations and dynamics are combined with the developed control law based on the discrete form of the super-twisting that is a second-order SM algorithm. Besides the good properties of this algorithm, the proposed combination ensures stability while choosing small super-twisting gains without a priori knowledge of the upper bound of the uncertainties. In addition, to the author's best knowledge, few works considered this algorithm in the control part.

- The proposed Discrete-time Terminal Super-Twisting Control (DTSTC) combined with the TDE are implemented in real-time on a real asymmetrical six-phase IM to support the theoretical developments, to improve the performance, and to demonstrate that it is appropriate for multiphase IM stator current control. The proposed discrete-time technique can be extended easily to any $n$-phase induction motor and generator. 
The rest of the manuscript is organized as follows. The continuous-time studied asymmetrical six-phase IM model and its discretization and the Voltage Source Converter (VSC) are detailed in Section 2. The developed discrete-time nonlinear technique is designed and the stability of the closed-loop system is analyzed in Section 3. In Section 4, the experimental results of four scenarios in transient and steady-state conditions are presented. Finally, Section 5 draws some conclusions.

\section{Preliminaries}

Consider the mathematical model of the asymmetrical six-phase IM powered by six-leg VSC $[17,18]$ represented in Figure 1:

$$
\begin{aligned}
\frac{d}{d t} i_{\alpha r}(t) & =-C_{2} R_{r} i_{\alpha r}(t)-C_{2} L_{r} \omega_{r}(t) i_{\beta r}(t)+C_{1} R_{s} i_{\alpha s}(t)-C_{2} L_{m} \omega_{r}(t) i_{\beta s}(t)-C_{1} v_{\alpha s}(t) \\
\frac{d}{d t} i_{\beta r}(t) & =C_{2} L_{r} \omega_{r}(t) i_{\alpha r}(t)-C_{2} R_{r} i_{\beta r}(t)+C_{2} L_{m} \omega_{r}(t) i_{\alpha s}(t)+C_{1} R_{s} i_{\beta s}(t)-C_{1} v_{\beta s}(t) \\
\frac{d}{d t} i_{\alpha s}(t) & =C_{1} R_{r} i_{\alpha r}(t)+C_{1} L_{r} \omega_{r}(t) i_{\beta r}(t)-C_{3} R_{s} i_{\alpha s}(t)+C_{1} L_{m} \omega_{r}(t) i_{\beta s}(t)+C_{3} v_{\alpha s}(t) \\
\frac{d}{d t} i_{\beta s}(t) & =-C_{1} L_{r} \omega_{r}(t) i_{\alpha r}(t)+C_{1} R_{r} i_{\beta r}(t)-C_{1} L_{m} \omega_{r}(t) i_{\alpha s}(t)-C_{3} R_{s} i_{\beta s}(t)+C_{3} v_{\beta s}(t) \\
\frac{d}{d t} i_{x s}(t) & =-C_{4} R_{s} i_{x s}(t)+C_{4} v_{x s}(t) \\
\frac{d}{d t} i_{y s}(t) & =-C_{4} R_{s} i_{y s}(t)+C_{4} v_{y s}(t)
\end{aligned}
$$

where $v_{\alpha s}(t), v_{\beta s}(t), v_{x s}(t)$, and $v_{y s}(t)$ are the stator input voltages; $\left\{i_{\alpha r}(t), i_{\beta r}(t)\right\}$ and $\left\{i_{\alpha s}(t), i_{\beta s}(t)\right\}$ are the unmeasurable rotor currents and the stator currents in the flux/torque producing $\alpha-\beta$ subspace, respectively; $i_{x s}(t)$ and $i_{y s}(t)$ are the stator currents in the loss-producing $x-y$ subspace; the coefficients $C_{1}$ to $C_{4}$ are given by $C_{1}=\frac{L_{m}}{L_{r} L_{s}-L_{m}^{2}}$, $C_{2}=\frac{L_{s}}{L_{m}} C_{1}, C_{3}=\frac{L_{r}}{L_{m}} C_{1}$, and $C_{4}=\frac{1}{L_{l s}}$, with

$R_{S}$ as the resistance of the stator,

$R_{r} \quad$ as the resistance of the rotor,

$L_{m}$ as the magnetizing inductance,

$L_{S}$ as the inductance of the stator,

$L_{l s}$ as the leakage inductance of the stator, and

$L_{r} \quad$ as the inductance of the rotor;

and finally $\omega_{r}(t)$ denotes the rotor electrical speed that is described by

$$
\dot{\omega}_{r}(t)=-\frac{B_{M}}{J_{M}} \omega_{r}(t)+\frac{P_{p}}{J_{M}}\left(T_{e}(t)-T_{L}(t)\right)
$$

where $T_{e}(t)=3 P_{p}\left(\psi_{\alpha s}(t) i_{\beta s}(t)-\psi_{\beta s}(t) i_{\alpha s}(t)\right)$ is the generated torque with $P_{p}$ ass the number of pole pairs and $\psi_{\alpha s}(t)$ and $\psi_{\beta s}(t)$ as the stator fluxes, $T_{L}(t)$ is the load torque, and $B_{M}$ and $J_{M}$ are the coefficients of the friction and the inertia, respectively. 


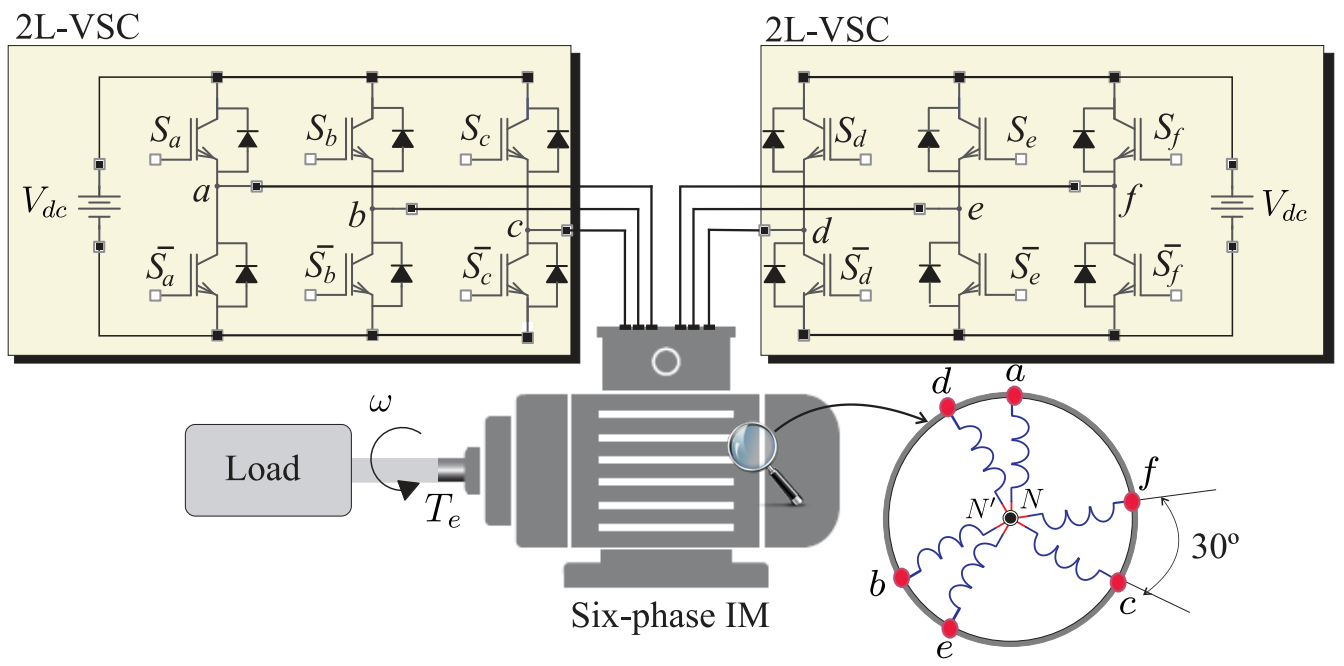

Figure 1. Studied six-phase IM powered by a six-leg VSC.

The considered system in Equation (1) is obtained using the vector space decomposition method that consists of the following transformation matrix:

$$
\mathbf{T}_{6}=\frac{1}{3}\left[\begin{array}{cccccc}
1 & \frac{\sqrt{3}}{2} & -\frac{1}{2} & -\frac{\sqrt{3}}{2} & -\frac{1}{2} & 0 \\
0 & \frac{1}{2} & \frac{\sqrt{3}}{2} & \frac{1}{2} & -\frac{\sqrt{3}}{2} & -1 \\
1 & -\frac{\sqrt{3}}{2} & -\frac{1}{2} & \frac{\sqrt{3}}{2} & -\frac{1}{2} & 0 \\
0 & \frac{1}{2} & -\frac{\sqrt{3}}{2} & \frac{1}{2} & \frac{\sqrt{3}}{2} & -1 \\
1 & 0 & 1 & 0 & 1 & 0 \\
0 & 1 & 0 & 1 & 0 & 1
\end{array}\right] .
$$

Based on the Euler approximation method, the discrete-time model of the measured stator currents of the studied motor is obtained as follows:

$$
\mathbf{X}(k+1)=\mathbf{F}(k)+\mathbf{G} \mathbf{v}(k)+\mathbf{H}(k)
$$

where $\bullet(k)=\bullet\left(k T_{s}\right)$, with $T_{S}$ as a sufficiently small sampling period, and the $\alpha-\beta$ and $x-y$ stator currents represent the state vector:

$$
\mathbf{X}(k)=\left[i_{\alpha s}(k), i_{\beta s}(k), i_{x s}(k), i_{y s}(k)\right]^{T}
$$

while the known dynamics $\mathbf{F}(k)$ and $\mathbf{G}$ and the unknown dynamics $\mathbf{H}(k)$ are defined by

$$
\begin{gathered}
\mathbf{F}(k)=\left[\begin{array}{c}
\left(1-T s C_{3} R_{s}\right) i_{\alpha s}(k)+T_{s} C_{1} L_{m} \omega_{r}(k) i_{\beta s}(k) \\
-T_{s} C_{1} L_{m} \omega_{r}(k) i_{\alpha s}(k)+\left(1-T_{s} C_{3} R_{s}\right) i_{\beta s}(k) \\
\left(1-T_{s} C_{4} R_{s}\right) i_{s s}(k) \\
\left(1-T_{s} C_{4} R_{s}\right) i_{x y}(k)
\end{array}\right], \\
\mathbf{G}=\left[\begin{array}{cccc}
T s C_{3} & 0 & 0 & 0 \\
0 & T_{s} C_{3} & 0 & 0 \\
0 & 0 & T_{s} C_{4} & 0 \\
0 & 0 & 0 & T_{s} C_{4}
\end{array}\right], \\
\mathbf{H}(k)=\left[\begin{array}{c}
T_{s} C_{1} R_{r} i_{\alpha r}(k)+T_{s} C_{1} L_{r} \omega_{r}(k) i_{\beta r}(k)+n_{\alpha s}(k) \\
-T_{s} C_{1} L_{r} \omega_{r}(k) i_{\alpha r}(k)+T_{s} C_{1} R_{r} i_{\beta r}(k)+n_{\beta s}(k) \\
n_{x s}(k) \\
n_{y s}(k)
\end{array}\right],
\end{gathered}
$$


with $n_{\bullet s}(k)$ as the matched disturbance acting on the $i_{\bullet s}(k)$ stator current. Notice that $H_{i}(k)=O\left(T_{s}\right)$ is bounded $\left|H_{i}(k)\right| \leq T_{s} \varrho_{i}<\infty$ and is of the order one with respect to the sampling time. Finally, the input vector is defined by

$$
\mathbf{v}(k)=\left[v_{\alpha s}(k), v_{\beta s}(k), v_{x s}(k), v_{y s}(k)\right]^{T} .
$$

Due to the following VSC model, we have

$$
\mathbf{M}=\frac{1}{3}\left[\begin{array}{cccccc}
2 & 0 & -1 & 0 & -1 & 0 \\
0 & 2 & 0 & -1 & 0 & -1 \\
-1 & 0 & 2 & 0 & -1 & 0 \\
0 & -1 & 0 & 2 & 0 & -1 \\
-1 & 0 & -1 & 0 & 2 & 0 \\
0 & -1 & 0 & -1 & 0 & 2
\end{array}\right]\left[\begin{array}{l}
S_{a} \\
S_{b} \\
S_{c} \\
S_{d} \\
S_{e} \\
S_{f}
\end{array}\right],
$$

where $S_{j}$ for $j=a, b, c, d, e, f$ is the gating signals that can switch between 0 and 1 . Finally, the above VSC model and the input vector (9) are linked by

$$
V_{\mathrm{dc}} \mathbf{T} \mathbf{M}=\mathbf{v}(k),
$$

where $V_{\mathrm{dc}}$ denotes the dc bus voltage.

\section{Enhanced DTSTC}

\subsection{Outer Speed Control Loop} PI [26]:

In this outer control loop, the mechanical speed is regulated using the following

$$
i_{q s}^{d}=K_{I} \frac{\left(\omega^{d}-\omega\right)}{s}+K_{P}\left(\omega^{d}-\omega\right) .
$$

It can be noticed from the above equation that the PI regulator generates the desired dynamic current $i_{q s}^{d}$ and then, as shown in the structure of closed-loop system (see Figure 2), the desired $\alpha-\beta$ stator currents are computed.

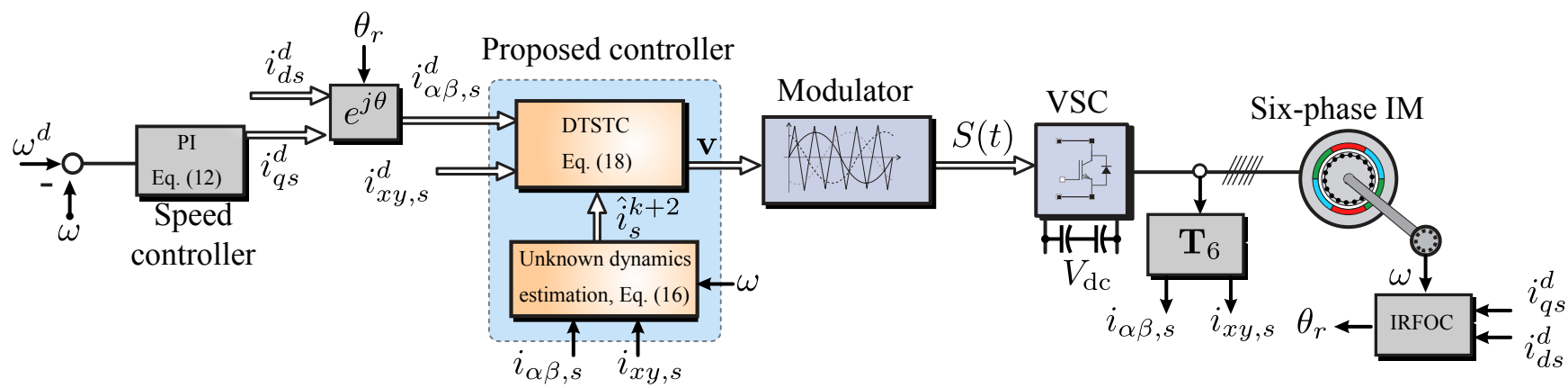

Figure 2. Scheme of the overall closed-loop control.

\subsection{Inner Current Control Loop}

In this part, the inner loop aims to ensure accurate $\alpha-\beta$ and $x-y$ stator currents tracking by designing a DTSTC law even if the $\alpha-\beta$ rotor currents are not measurable and in the presence if the matched perturbations. In one hand, the discrete terminal sliding function is defined by:

$$
\mathbf{S}(k)=\mathbf{E}(k)+\boldsymbol{\Lambda}_{1} \mathbf{E}(k-1)+\boldsymbol{\Lambda}_{2} \mathbf{S i g}^{\gamma}(\mathbf{E}(k-1)) .
$$

where $\mathbf{E}(k)=\mathbf{X}(k)-\mathbf{X}^{d}(k)$ is the current tracking error with $\mathbf{X}^{d}(k)=\left[i_{\alpha s}^{d}(k), i_{\beta s}^{d}(k), i_{x s}^{d}(k)\right.$, $\left.i_{y s}^{d}(k)\right]^{T}$ as the desired stator current vector; $\Lambda_{1}$ and $\Lambda_{2}$ are two $(4 \times 4)$ positive definite di- 
agonal matrices; and $\operatorname{Sig}^{\gamma}(\mathbf{E}(k-1))=\left[\left|E_{1}(k-1)\right|^{\gamma_{1}} \operatorname{sign}\left(E_{1}(k-1)\right), \cdots,\left|E_{4}(k-1)\right|^{\gamma_{4}} \operatorname{sign}\right.$ $\left.\left(E_{4}(k-1)\right)\right]^{T}$, with $\gamma_{i} \in(0,1)$ for $i=1, \cdots, 4$ such that

$$
\operatorname{Sig}^{0}\left(\mathbf{E}_{i}(k)\right)=\left\{\begin{aligned}
0, & \text { if } E_{i}(k)=0 \\
-1, & \text { if } E_{i}(k)<0 \\
1, & \text { if } E_{i}(k)>0
\end{aligned}\right.
$$

Then, $\mathbf{S}(k+1)$ is computed as follows:

$$
\begin{aligned}
\mathbf{S}(k+1) & =\mathbf{E}(k+1)+\Lambda_{1} \mathbf{E}(k)+\boldsymbol{\Lambda}_{2} \mathbf{S i g}^{\gamma}(\mathbf{E}(k)) \\
& =\mathbf{X}(k+1)-\mathbf{X}^{d}(k+1)+\boldsymbol{\Lambda}_{1} \mathbf{E}(k)+\boldsymbol{\Lambda}_{2} \mathbf{S i g}^{\gamma}(\mathbf{E}(k)) \\
& =\mathbf{F}(k)+\mathbf{G} \mathbf{v}(k)+\hat{\mathbf{H}}(k)-\mathbf{X}^{d}(k+1)+\Lambda_{1} \mathbf{E}(k)+\boldsymbol{\Lambda}_{2} \mathbf{S i g}^{\gamma}(\mathbf{E}(k)),
\end{aligned}
$$

where $\hat{\mathbf{H}}(k)$ is the estimate vector of $\mathbf{H}(k)$ obtained using the TDE method defined as in [27]:

$$
\hat{\mathbf{H}}(k) \cong \mathbf{H}(k-1)=\mathbf{X}(k)-\mathbf{F}(k-1)+\mathbf{G} \mathbf{v}(k-1) .
$$

As said before, the above estimation is accurate if and only if the variations in the functions of the vector $\mathbf{H}(k)$ are small during two consecutive sampling times. Moreover, adding this estimation to the control law ensures better performances and allows for the choice of smaller control gains that result in low control efforts.

On the other hand, the discrete super-twisting algorithm is defined by the following:

$$
\begin{aligned}
\mathbf{S}(k+1) & =\mathbf{Q}_{1} \mathbf{S}(k)-T_{s} \mathbf{Q}_{2} \operatorname{Sig}^{0.5}(\mathbf{S}(k))+T_{s} \mathbf{R}(k) \\
\mathbf{R}(k+1) & =\mathbf{Q}_{3} \mathbf{R}(k)-T_{s} \mathbf{Q}_{4} \operatorname{Sig}^{0}(\mathbf{S}(k))
\end{aligned}
$$

where $\mathbf{Q}_{1}=\operatorname{diag}\left(Q_{11}, \cdots, Q_{14}\right), \mathbf{Q}_{2}=\operatorname{diag}\left(Q_{21}, \cdots, Q_{24}\right), \mathbf{Q}_{3}=\operatorname{diag}\left(Q_{31}, \cdots, Q_{34}\right)$, and $\mathbf{Q}_{4}=\operatorname{diag}\left(Q_{41}, \cdots, Q_{44}\right)$ are diagonal positive matrices, where the elements of $\mathbf{Q}_{1}$ and $\mathbf{Q}_{3}$ are $\in(0,1)$ while the elements of $\mathbf{Q}_{2}$ and $\mathbf{Q}_{4}$ are fixed in the proof.

Hence, combining Equations (15) and (17) yields the following:

$$
\begin{aligned}
\mathbf{v}(k) & =-\mathbf{G}^{-1}\left[\mathbf{F}(k)+\hat{\mathbf{H}}(k)-\mathbf{X}^{d}(k+1)-\mathbf{Q}_{1} \mathbf{S}(k)+T_{s} \mathbf{Q}_{2} \operatorname{Sig}^{0.5}(\mathbf{S}(k))-T_{s} \mathbf{R}(k)\right] \\
\mathbf{R}(k+1) & =\mathbf{Q}_{3} \mathbf{R}(k)-T_{s} \mathbf{Q}_{4} \operatorname{Sig}^{0}(\mathbf{S}(k)) .
\end{aligned}
$$

Theorem 1. Consider the discrete-time model of the measured stator currents of the six-phase IM system (5) if the conditions below are met for $i=1, \cdots, 4$ :

$$
\begin{gathered}
Q_{2 i}>0, \\
Q_{4 i}>\frac{\left(1+Q_{3 i}\right)}{T_{s}} \delta h_{i} .
\end{gathered}
$$

Then, the developed DTSTC law computed in Equation (18) guarantees convergence of each stator current tracking error to a ball in the vicinity of the equilibrium point such that the maximal value of his radius is given by

$$
r_{\text {max }}=\frac{\left(0.25\left(\sigma_{2}+\sigma_{3}\right)^{2}\left\|\bar{L}^{-1}\right\|^{2}+\sigma_{1}+\sigma_{2}\right)}{\delta} .
$$

Proof of Theorem 1. Substituting the computed DTSTC (18) into the measured stator currents dynamics (5) gives

$$
\begin{aligned}
\mathbf{S}(k+1) & =\mathbf{Q}_{1} \mathbf{S}(k)-T_{s} \mathbf{Q}_{2} \operatorname{Sig}^{0.5}(\mathbf{S}(k))+T_{s} \mathbf{R}(k)+\Delta \mathbf{H}(k) \\
\mathbf{R}(k+1) & =\mathbf{Q}_{3} \mathbf{R}(k)-T_{s} \mathbf{Q}_{4} \operatorname{Sig}^{0}(\mathbf{S}(k))
\end{aligned}
$$


where $\tilde{\mathbf{H}}(k)=\mathbf{H}(k)-\mathbf{H}(k-1)=O\left(T_{s}^{2}\right)$ is the estimation error that is bounded such that, for $i=1, \cdots, 4$,

$$
\left|\tilde{H}_{i}(k)\right| \leq T_{s} \delta h_{i}
$$

where $T_{s} \delta h_{i}$ is a positive constant smaller than $T_{s} \varrho_{i}$ that is the upper bound of $H_{i}(k)$.

For each stator current $(i=1, \cdots, 4)$, the closed-loop error dynamics can be expressed as a subsystem:

$$
\begin{aligned}
S_{i}(k+1) & =Q_{1 i} S_{i}(k)-T_{s} Q_{2 i}\left|S_{i}(k)\right|^{0.5} \operatorname{sign}\left(S_{i}(k)\right)+\tilde{H}_{i}(k)+T_{s} R_{i}(k) \\
R_{i}(k+1) & =Q_{3 i} R_{i}(k)-T_{s} Q_{4 i} \operatorname{sign}\left(S_{i}(k)\right)
\end{aligned}
$$

To simplify the proof, a new variable is introduced $W_{i}(k)=R_{i}(k)+T_{s}^{-1} \tilde{H}_{i}(k)$; then, the above equation can be rewritten in a matrix form as follows:

$$
\begin{aligned}
\underbrace{\left[\begin{array}{c}
S_{i}(k+1) \\
W_{i}(k+1)
\end{array}\right]}_{Y_{i}(k+1)}=\underbrace{\left[\begin{array}{cc}
Q_{1 i} & T_{S} \\
0 & Q_{3 i}
\end{array}\right]}_{A} \underbrace{\left[\begin{array}{c}
S_{i}(k) \\
W_{i}(k)
\end{array}\right]}_{Y_{i}(k)}+\underbrace{\left[\begin{array}{c}
-T_{S} Q_{2 i}\left|S_{i}(k)\right|^{0.5} \\
-T_{S} Q_{4 i}+Z_{i}(k) \operatorname{sign}\left(S_{i}(k)\right)
\end{array}\right]}_{B(k)} \operatorname{sign}\left(S_{i}(k)\right) \\
Z_{i}(k)=T_{S}^{-1}\left(\tilde{H}_{i}(k+1)-Q_{3 i} \tilde{H}_{i}(k)\right)
\end{aligned}
$$

such that $Z_{i}(k)$ is bounded as follows:

$$
\begin{aligned}
Z_{i}(k) & =T_{s}^{-1}\left(\tilde{H}_{i}(k+1)-Q_{3 i} \tilde{H}_{i}(k)\right) \\
& \leq T_{s}^{-1}\left|\tilde{H}_{i}(k+1)-Q_{3 i} \tilde{H}_{i}(k)\right| \\
& \leq T_{s}^{-1}\left(\left|\tilde{H}_{i}(k+1)\right|+Q_{3 i}\left|\tilde{H}_{i}(k)\right|\right) \\
& \leq T_{s}^{-1}\left(T_{s} \delta h_{i}+Q_{3 i} T_{s} \delta h_{i}\right) \\
& \leq \delta h_{i}\left(1+Q_{3 i}\right)
\end{aligned}
$$

Once the discrete closed-loop error dynamics for each stator current is formulated, the following discrete Lyapunov function is selected:

$$
V(k)=Y_{i}^{T}(k) P Y_{i}(k)
$$

where $P=P^{T} \in R^{2 \times 2}$ is a symmetric definite positive matrix. Notice that the same $P$ matrix can be chosen for all currents stability analyses. Then,

$$
\begin{aligned}
\Delta V(k) & =V(k+1)-V(k) \\
& =Y_{i}^{T}(k+1) P Y_{i}(k+1)-Y_{i}^{T}(k) P Y_{i}(k)
\end{aligned}
$$

Substituting Equation (25) into (29) yields

$$
\Delta V(k)=Y_{i}^{T}(k)\left(A^{T} P A-P\right) Y_{i}(k)+B^{T}(k) P B(k)+2 Y_{i}^{T}(k) A^{T} P B(k) \operatorname{sign}\left(S_{i}(k)\right) .
$$

Using the following $\Gamma$-matrix inequality [28]

$$
A^{T} B+B^{T} A \leq A^{T} \Gamma A+B^{T} \Gamma^{-1} B,
$$

Equation (25) becomes

$$
\begin{aligned}
\Delta V(k) & \leq Y_{i}^{T}(k)\left(A^{T} P A-P\right) Y_{i}(k)+B^{T}(k) P B(k)+Y_{i}^{T}(k)\left(A^{T} P \Gamma P A\right) Y_{i}(k)+B^{T}(k) \Gamma^{-1} B(k) \\
& \leq Y_{i}^{T}(k)\left(A^{T}(P+P \Gamma P) A-(1-\delta) P\right) Y_{i}(k)+B^{T}(k)\left(P+\Gamma^{-1}\right) B(k)-\delta V(k) \\
& \leq-Y_{i}^{T}(k) L Y_{i}(k)+B^{T}(k)\left(P+\Gamma^{-1}\right) B(k)-\delta V(k)
\end{aligned}
$$


where $\delta \in(0,1)$ and $L \in R^{2 \times 2}$ is a symmetric definite positive matrix that solves the following:

$$
L=-A^{T}(P+P \Gamma P) A-(\delta-1) P .
$$

Moreover, taking into account the conditions in (19), the term $B^{T}(k)\left(P+\Gamma^{-1}\right) B(k)$ can be expanded as follows:

$$
\begin{aligned}
B^{T}(k) \underbrace{\left(P+\Gamma^{-1}\right)}_{M} B(k) & =\sigma_{1}+\sigma_{2}\left|S_{i}(k)\right|^{0.5}+\sigma_{3}\left|S_{i}(k)\right| \\
& \leq \sigma_{1}+\sigma_{2}\left(1+\left|S_{i}(k)\right|\right)+\sigma_{3}\left|S_{i}(k)\right| \\
& \leq \sigma_{1}+\sigma_{2}+\left(\sigma_{2}+\sigma_{3}\right)\left|S_{i}(k)\right|
\end{aligned}
$$

where

$$
\begin{aligned}
& \sigma_{1}=M_{22}\left[Z_{i}(k) \operatorname{sign}\left(S_{i}(k)\right)-T_{s} Q_{4 i}\right]^{2} \\
& \sigma_{2}=-2 T_{s} Q_{2 i} M_{21}\left[Z_{i}(k) \operatorname{sign}\left(S_{i}(k)\right)-T_{s} Q_{4 i}\right] \\
& \sigma_{3}=T_{s}^{2} Q_{2 i}^{2} M_{11} .
\end{aligned}
$$

Combining Equations (32) and (34) gives

$$
\Delta V(k) \leq-Y_{i}^{T}(k) L Y_{i}(k)+\sigma_{1}+\sigma_{2}+\left(\sigma_{2}+\sigma_{3}\right)\left|S_{i}(k)\right|-\delta V(k) .
$$

Then, based on Choleskii decomposition, the above equation becomes

$$
\begin{aligned}
\Delta V(k) \leq & -\left\|\bar{L} Y_{i}(k)\right\|^{2}+\left(\sigma_{2}+\sigma_{3}\right)\left\|\overline{L L}^{-1} Y_{i}(k)\right\|+\sigma_{1}+\sigma_{2}-\delta V(k) \\
\leq & -\left(\left\|\bar{L} Y_{i}(k)\right\|-0.5\left(\sigma_{2}+\sigma_{3}\right)\left\|\bar{L}^{-1}\right\|\right)^{T}\left(\left\|\bar{L} Y_{i}(k)\right\|-0.5\left(\sigma_{2}+\sigma_{3}\right)\left\|\bar{L}^{-1}\right\|\right) \\
& +0.25\left(\sigma_{2}+\sigma_{3}\right)^{2}\left\|\bar{L}^{-1}\right\|^{2}+\sigma_{1}+\sigma_{2}-\delta V(k) \\
\leq & 0.25\left(\sigma_{2}+\sigma_{3}\right)^{2}\left\|\bar{L}^{-1}\right\|^{2}+\sigma_{1}+\sigma_{2}-\delta V(k) \\
V(k+1) \leq & 0.25\left(\sigma_{2}+\sigma_{3}\right)^{2}\left\|\bar{L}^{-1}\right\|^{2}+\sigma_{1}+\sigma_{2}+(1-\delta) V(k)
\end{aligned}
$$

where $\bar{L}^{2}=L$. The discrete-time inequality in Equation (37) has a solution that can be expressed as follows:

$$
V(k+1) \leq\left(0.25\left(\sigma_{2}+\sigma_{3}\right)^{2}\left\|\bar{L}^{-1}\right\|^{2}+\sigma_{1}+\sigma_{2}\right) \sum_{j=1}^{k+1}(1-\delta)^{j-1}+(1-\delta)^{k+1} V(0)
$$

such that, when $k$ converges to $\infty$, we have

$$
\lim _{k \rightarrow+\infty} V(k) \leq \frac{\left(0.25\left(\sigma_{2}+\sigma_{3}\right)^{2}\left\|\bar{L}^{-1}\right\|^{2}+\sigma_{1}+\sigma_{2}\right)}{\delta} .
$$

Hence, DTSTC guarantees convergence of the stator currents into a ball region with a radius smaller than the maximal value given in Equation (21). This concludes the proof of Theorem 1.

\section{Experimental Results}

The developed DTSTC supported by the TDE method was implemented in real-time to validate its performance. The used practical system was a $2 \mathrm{~kW}$ six-phase IM with a nominal mechanical speed of $3000 \mathrm{rpm}$. The dc power that supplies the system provides a constant dc bus voltage. The two three-phase VSCs were commanded by a dSPACE 
MABXII DS1401 real-time rapid prototyping platform with Simulink. The identified parameters of the machine are given in Table 1.

Table 1. Six-phase IM parameters.

\begin{tabular}{cccccc}
\hline Parameter & Value & Unit & Parameter & Value & Unit \\
\hline$R_{r}$ & 7.0 & $\Omega$ & $L_{s}$ & 654.4 & $\mathrm{mH}$ \\
$R_{s}$ & 6.7 & $\Omega$ & $J_{M}$ & 0.07 & $\mathrm{~kg} \cdot \mathrm{m}^{2}$ \\
$L_{l s}$ & 5.85 & $\mathrm{mH}$ & $B_{M}$ & 0.0004 & $\mathrm{~kg} \cdot \mathrm{m}^{2}$ \\
$L_{m}$ & 708.5 & $\mathrm{mH}$ & $V_{\mathrm{dc}}$ & 400 & $\mathrm{~V}$ \\
$L_{r}$ & 626.8 & $\mathrm{mH}$ & $P_{p}$ & 1 & - \\
\hline
\end{tabular}

The current sensors LA 55-P s with a frequency bandwidth from dc up to $200 \mathrm{kHz}$ was used in the practical tests. Based on a 16-bit A/D converter, we converted the measurement of the currents to digital. Moreover, the rotor speed was estimated from the position obtained with a $1024 \mathrm{ppr}$ incremental encoder. Finally, a variable mechanical load acting on the used motor was introduced using a 5 HP eddy current brake. The equipment of the experimental setup is depicted in Figure 3.

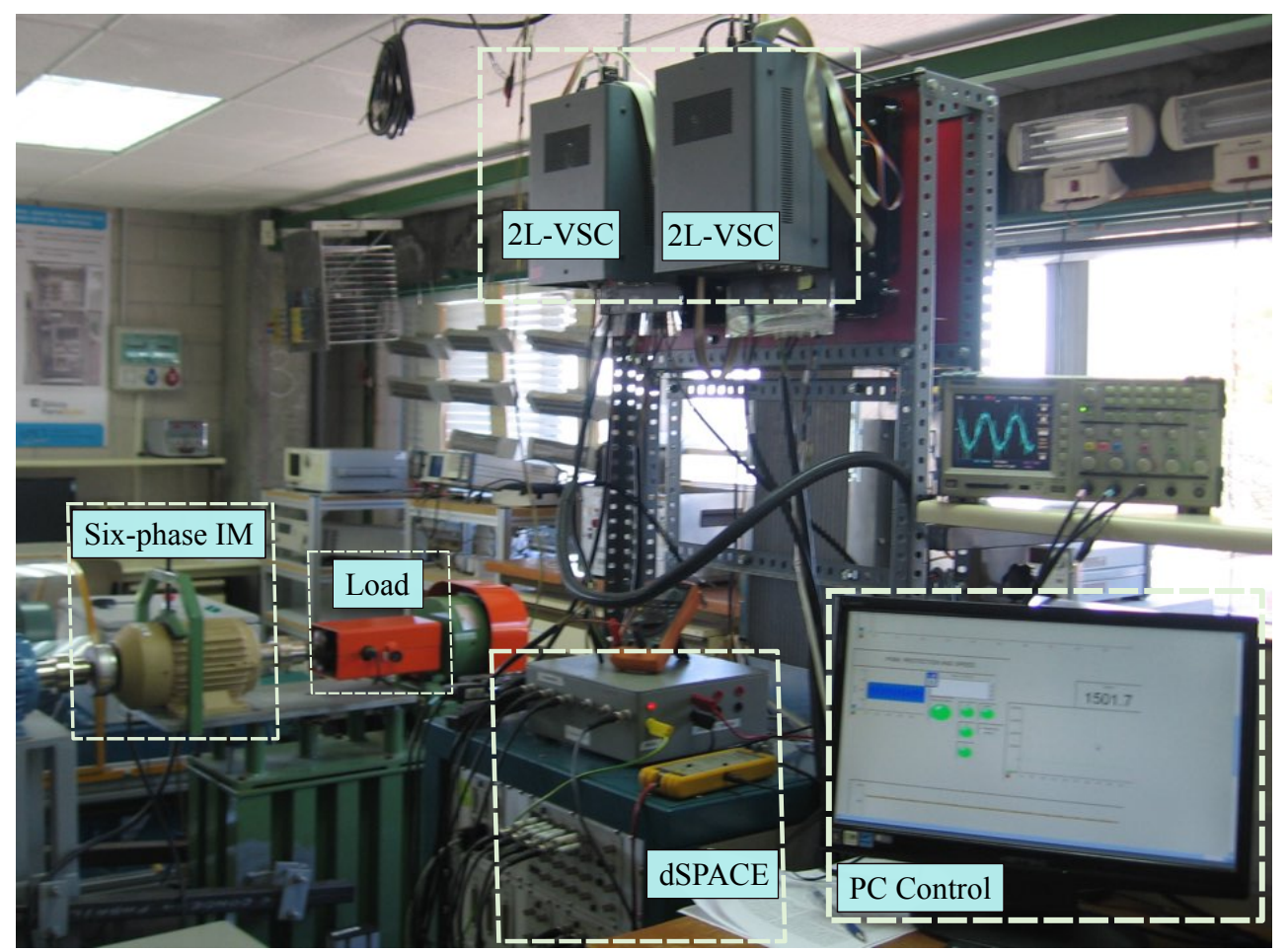

Figure 3. Experimental setup.

The performance of the proposed discrete-time technique was analyzed in steady-state and transient conditions with a sampling frequency of $8 \mathrm{kHz}$. Three steady-state tests were performed respectively for two desired speeds $1000 \mathrm{rpm}$ and $1500 \mathrm{rpm}$. In addition, two transient tests were performed with a change from $1000 \mathrm{rpm}$ to $-500 \mathrm{rpm}$ and then a second step change from $-500 \mathrm{rpm}$ to $1000 \mathrm{rpm}$. In these tests, the desired $d$ current was settled to $1 \mathrm{~A}$. Moreover, a mechanical load was performed by fixing the eddy current brake at $1.65 \mathrm{~A}$. Finally, to reduce the copper losses, the desired $x-y$ stator currents were set to $0 \mathrm{~A}$. During these tests, the proposed controller gains were tuned manually while checking the control performance by trial and error and were finally selected as

$$
\boldsymbol{\Lambda}_{1}=\boldsymbol{\Lambda}_{2}=\operatorname{diag}(0.2,0.2,0.2,0.2), \quad \gamma_{i}=0.8 \text { for } i=1, \cdots, 4,
$$




$$
\begin{gathered}
\mathbf{Q}_{1}=\mathbf{Q}_{3}=\operatorname{diag}(0.7,0.7,0.7,0.7), \quad \mathbf{Q}_{2}=T_{s}^{-1} \operatorname{diag}(0.5,0.5,0.5,0.5), \\
\mathbf{Q}_{4}=T_{s}^{-1} \operatorname{diag}(0.3,0.3,0.3,0.3) .
\end{gathered}
$$

The results for the steady-state tests are depicted in Figure 4. In these figures as well as in Figures 5 and 6 , the blue signals represent the measured $\{q, \alpha, \beta\}$ stator currents, the red signals represent the desired $\{q, \alpha, \beta\}$ stator currents, while the black signals represent the measured $\{x, y\}$ stator currents. The results in all the figures showed good tracking of the stator currents. Moreover, the results for the transient tests are shown in Figure 5. It is clear that the developed DTSTC ensures high-accuracy stator currents tracking in the $\alpha-\beta, x-y$ planes similar to that for the previous tests. Then, the same scenarios were performed while considering a $25 \%$ variation in magnetizing inductance to demonstrate the insensitivity of the proposed method to parameter variations [29]. Notice that the variation in $L_{m}$ implies a variation in the whole dynamics since the coefficients $C_{1}, C_{2}$ and $C_{3}$ are in terms of this inductance. The results shown in Figure 6 prove the robustness of the developed discrete method against parameter variations.
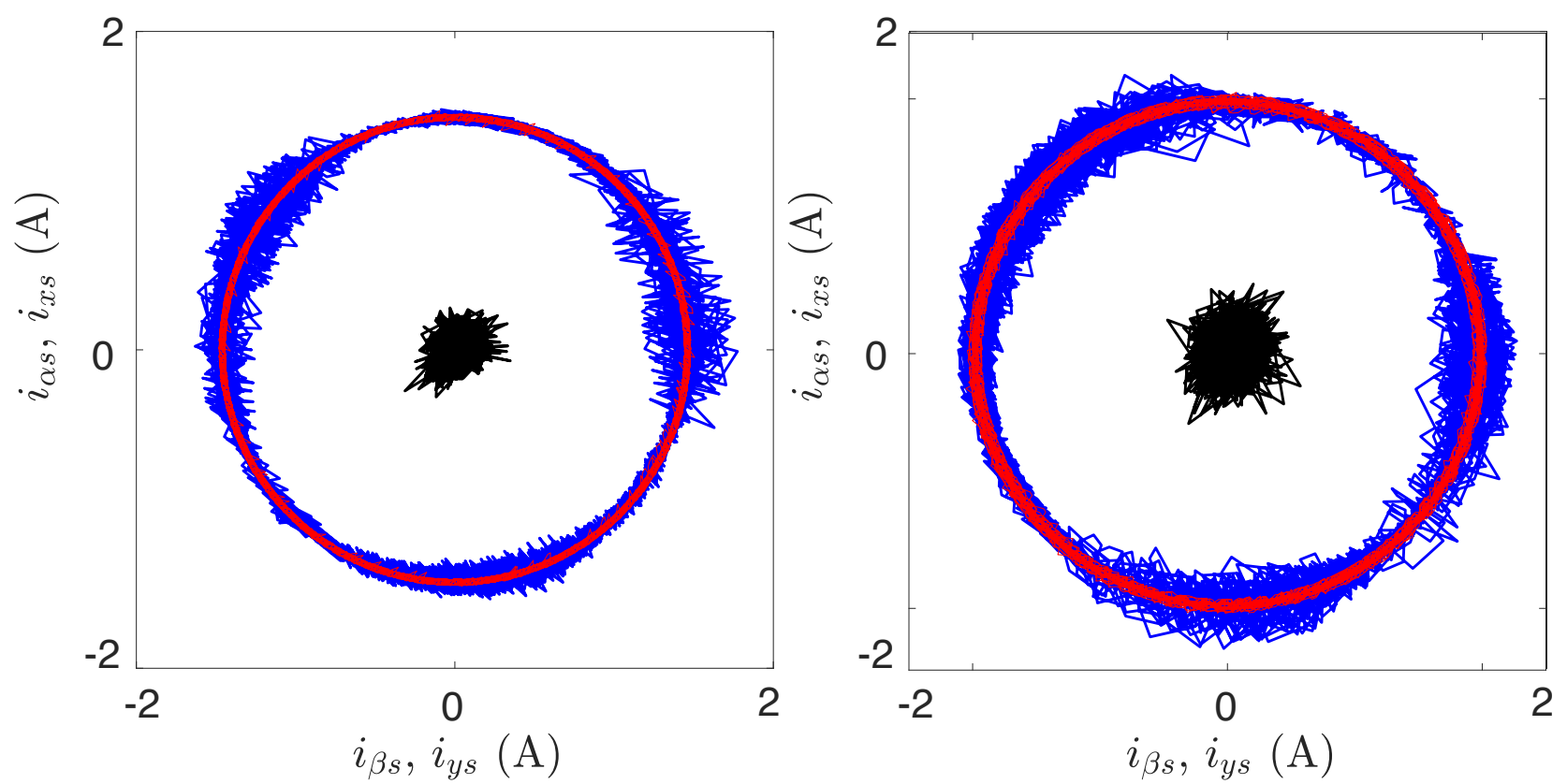

Figure 4. Steady-state response of $\{\alpha, x, \beta, y\}$ stator currents for two different desired rotor speed $\omega_{r}^{d}$ : results from left to right for 1000 and $1500 \mathrm{rpm}$.

The performance of the developed discrete-time method was compared to the TDEbased DSMC [17] in steady state for two operating points, 1000 and 1500 (rpm), based on the Mean Squared Error (MSE) index defined for $i=1, \cdots, 4$ by

$$
\operatorname{MSE}\left(X_{i}\right)=\sqrt{\frac{1}{N} \sum_{k=1}^{N} E_{i}(k)^{2}},
$$

where $N$ is the total number of analyzed samples. The results of this comparative study are listed in Table 2 and show the obtained MSE values for the stator currents in $\alpha-\beta$ and $x-y$ subspaces. The data show that better performances are obtained with the proposed algorithm over the existing TDE-based DSMC. 
Table 2. Quantitative comparison of the MSE of the $\{\alpha, \beta, x, y\}$ stator currents performance for two different rotor speed references.

\begin{tabular}{lcccc}
\hline Poposed DTSTC & & & & \\
\hline$\omega_{r}^{d}(\mathrm{rpm})$ & $\operatorname{MSE}_{i_{\alpha s}}(A)$ & $\operatorname{MSE}_{i_{\beta s}}(A)$ & $\operatorname{MSE}_{i_{x s}}(A)$ & $\operatorname{MSE}_{i_{y s}}(A)$ \\
\hline 1000 & 0.2937 & 0.3021 & 0.2326 & 0.2280 \\
1500 & 0.3000 & 0.3050 & 0.2491 & 0.2456 \\
\hline TDE-based DSMC [17] & & & & \\
\hline$\omega_{r}^{d}(\mathrm{rpm})$ & $\operatorname{MSE}_{i_{\alpha s}}(A)$ & $\operatorname{MSE}_{i_{s s}}(A)$ & $\operatorname{MSE}_{i_{x s}}(A)$ & $\operatorname{MSE}_{i_{y s}}(A)$ \\
\hline 1000 & 0.0883 & 0.0795 & 0.0401 & 0.0457 \\
1500 & 0.1813 & 0.1649 & 0.1107 & 0.1000 \\
\hline
\end{tabular}
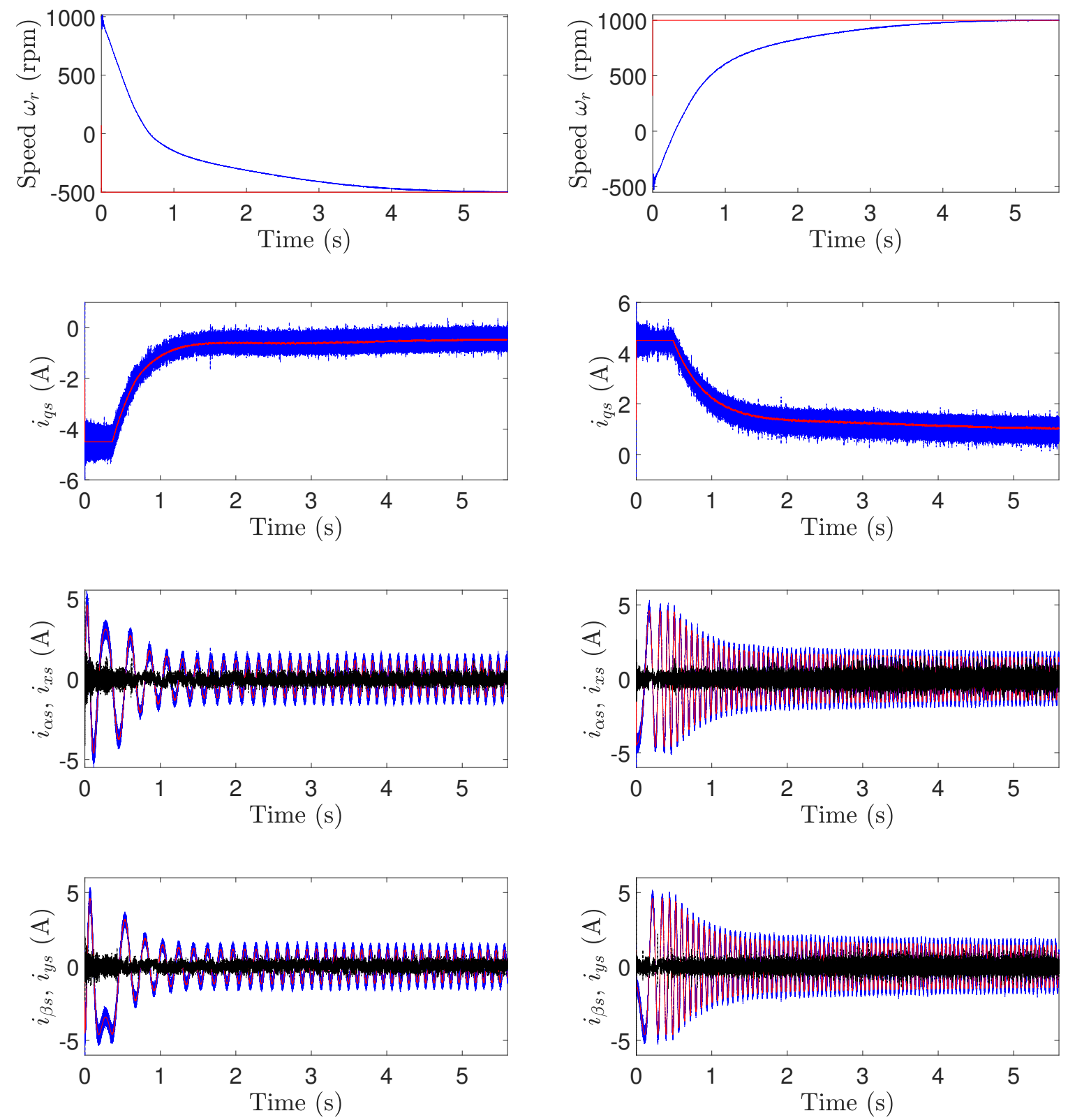

Figure 5. Transient response of $\{q, \alpha, x, \beta, y\}$ stator currents for two different desired step rotor speeds $\omega_{r}^{d}$ : results from 1000 to $-500 \mathrm{rpm}$ in the left column and from -500 to $1000 \mathrm{rpm}$ in the right column. 

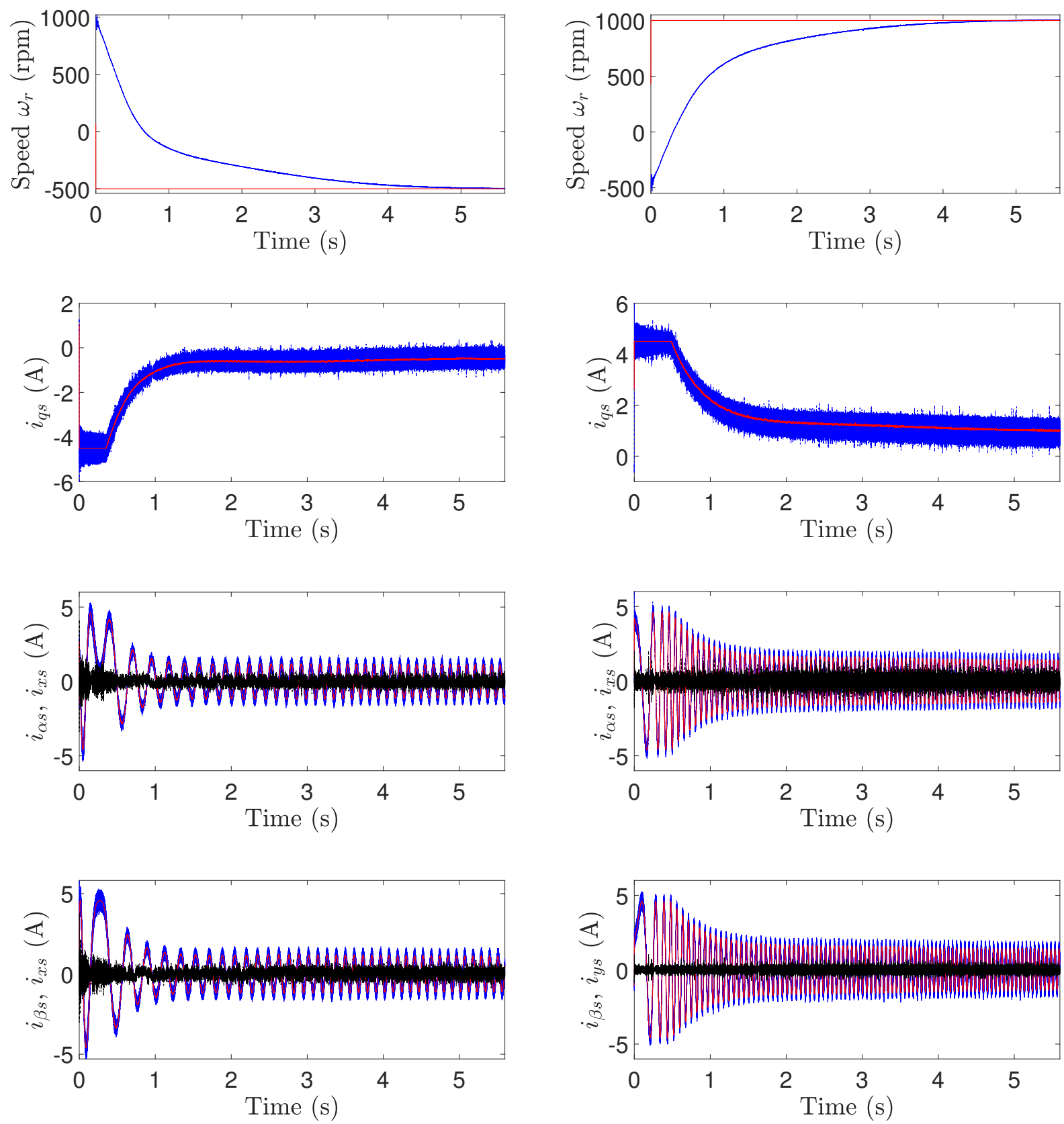

Figure 6. Transient response of $\{q, \alpha, x, \beta, y\}$ stator currents for two different desired step rotor speeds $\omega_{r}^{d}$ with a variation of $25 \%$ on the magnetizing inductance: results from 1000 to $-500 \mathrm{rpm}$ in the left column and from -500 to $1000 \mathrm{rpm}$ in the right column.

\section{Conclusions}

In this work, speed control based on an indirect rotor field-oriented control strategy with an inner DTSTC for the $\alpha-\beta$ and the $x-y$ stator currents was developed. The proposed technique was supported by the TDE method to simply approximate the matched perturbations and the $\alpha-\beta$ unmeasurable rotor current. The developed discrete terminal super-twisting rejects the nonlinearities caused by the estimation error and ensures accurate stator currents tracking and fast convergence of this latter to zero. The effectiveness of this discrete technique was shown in the theoretical development and experimental work conducted on a real asymmetrical six-phase induction motor. Indeed, the developed method produces excellent performances in steady state and transient state as well. Further 
research will be initiated to extend the development for a multiphase induction motor in faulty conditions since operating in faulty situations is one of the benefits of these machines. The extended work aims is to ensure high performance under fault condition without acting on the control law.

Author Contributions: Conceptualization, Y.K., M.S., and J.R.; methodology, Y.K., M.S., and J.R.; software, Y.K. and J.D.-G.; validation, J.D.-G.; formal analysis, Y.K., M.S., J.D.-G., and J.R.; investigation, Y.K. and M.S.; resources, J.D.-G.; data curation, J.D.-G.; writing—original draft preparation, Y.K. and M.S.; writing-review and editing, Y.K., M.S., J.D.-G., and J.R.; visualization, J.D.G; project administration, M.S. and J.D.-G. All authors have read and agreed to the published version of the manuscript.

Funding: This work was supported in part by the Spanish State Research Agency (AEI) under project PID2019-105612RB-I00/AEI/10.13039/501100011033.

Institutional Review Board Statement: Not applicable.

Informed Consent Statement: Not applicable.

Data Availability Statement: Not applicable.

Conflicts of Interest: The authors declare no conflict of interest.

$\begin{array}{ll}\text { Abbreviations } \\ \text { The following abbreviations are used in this manuscil } \\ \text { dc } & \text { Direct current } \\ \text { DQSM } & \text { Discrete-time quasi-sliding mode } \\ \text { DTSTC } & \text { Discrete terminal super-twisting control } \\ \text { IM } & \text { Induction motor } \\ \text { MSE } & \text { Mean squared error } \\ \text { PI } & \text { Proportional-integral } \\ \text { QSMB } & \text { Quasi sliding mode band } \\ \text { SM } & \text { Sliding mode } \\ \text { TDE } & \text { Time-delay estimation } \\ \text { VSC } & \text { Voltage source converter }\end{array}$

\section{References}

1. Kali, Y.; Saad, M.; Rodas, J.; Mougharbel, I.; Benjelloun, K. Robust Control of a 6-Phase Induction Generator for Variable Speed Wind Energy Conversion System. In Proceedings of the 2020 th International Conference on Renewable Energies for Developing Countries (REDEC), Marrakech, Morocco, 29-30 June 2020; pp. 1-6. [CrossRef]

2. Yu, F.; Cheng, M.; Chau, K.; Li, F. Control and Performance Evaluation of Multiphase FSPM Motor in Low-Speed Region for Hybrid Electric Vehicles. Energies 2015, 8, 10335-10353. [CrossRef]

3. Liu, Z.; Wu, J.; Hao, L. Coordinated and fault-tolerant control of tandem 15-phase induction motors in ship propulsion system. IET Electr. Power Appl. 2018, 12, 91-97. [CrossRef]

4. Jung, E.; Yoo, H.; Sul, S.; Choi, H.; Choi, Y. A Nine-Phase Permanent-Magnet Motor Drive System for an Ultrahigh-Speed Elevator. IEEE Trans. Ind. Appl. 2012, 48, 987-995. [CrossRef]

5. Barrero, F.; Duran, M.J. Recent Advances in the Design, Modeling, and Control of Multiphase Machines: Part I. IEEE Trans. Ind. Electron. 2016, 63, 449-458. [CrossRef]

6. Duran, M.J.; Barrero, F. Recent Advances in the Design, Modeling, and Control of Multiphase Machines: Part II. IEEE Trans. Ind. Electron. 2016, 63, 459-468. [CrossRef]

7. Levi, E. Advances in Converter Control and Innovative Exploitation of Additional Degrees of Freedom for Multiphase Machines. IEEE Trans. Ind. Electron. 2016, 63, 433-448. [CrossRef]

8. Lim, C.; Levi, E.; Jones, M.; Rahim, N.; Hew, W.P. FCS-MPC based current control of a five-phase induction motor and its comparison with PI-PWM control. IEEE Trans. Ind. Electron. 2014, 61, 149-163. [CrossRef]

9. Taheri, A.; Rahmati, A.; Kaboli, S. Efficiency improvement in DTC of six-phase induction machine by adaptive gradient descent of flux. IEEE Trans. Power Electron. 2012, 27, 1552-1562. [CrossRef]

10. Rodas, J.; Barrero, F.; Arahal, M.R.; Martín, C.; Gregor, R. Online estimation of rotor variables in predictive current controllers: a case study using five-phase induction machines. IEEE Trans. Ind. Electron. 2016, 63, 5348-5356. [CrossRef]

11. Rodas, J.; Martín, C.; Arahal, M.R.; Barrero, F.; Gregor, R. Influence of Covariance-Based ALS Methods in the Performance of Predictive Controllers with Rotor Current Estimation. IEEE Trans. Ind. Electron. 2017, 64, 2602-2607. [CrossRef] 
12. Elbarbary, Z.; Azeem, M.F.; Azazi, H.Z. Adaptive Fuzzy-Based IRFOC of Speed Sensorless Six-Phase Induction Motor Drive System. J. Circuits, Syst. Comput. 2020, 29, 2050062. [CrossRef]

13. Raja, D.; Ravi, G. Dynamic modeling and control of five phase SVPWM inverter fed induction motor drive with intelligent speed controller. J. Ambient. Intell. Humaniz. Comput. 2020, 1-11. [CrossRef]

14. Kali, Y.; Rodas, J.; Saad, M.; Doval-Gandoy, J.; Gregor, R. Nonlinear Backstepping with Time Delay Estimation for Six-Phase Induction Machine. In Proceedings of the 2019 IEEE International Electric Machines Drives Conference (IEMDC), San Diego, CA, USA, 12-15 May 2019; pp. 1798-1804. [CrossRef]

15. Morawiec, M.; Strankowski, P.; Lewicki, A.; Guziński, J.; Wilczyński, F. Feedback Control of Multiphase Induction Machines With Backstepping Technique. IEEE Trans. Ind. Electron. 2020, 67, 4305-4314. [CrossRef]

16. Kali, Y.; Rodas, J.; Saad, M.; Gregor, R.; Doval-Gandoy, J.; Benjelloun, K. Comparative Study of Time Delay Estimation Based Optimal 1st and 2nd Order Sliding Mode for Current Regulation of Six-Phase Induction Machines. In Proceedings of the IECON 2019-45th Annual Conference of the IEEE Industrial Electronics Society, Lisbon, Portugal, 14-17 October 2019; Volume 1, pp. 6194-6199. [CrossRef]

17. Kali, Y.; Ayala, M.; Rodas, J.; Saad, M.; Doval-Gandoy, J.; Gregor, R.; Benjelloun, K. Current Control of a Six-Phase Induction Machine Drive Based on Discrete-Time Sliding Mode with Time Delay Estimation. Energies 2019, 12, 170. [CrossRef]

18. Kali, Y.; Saad, M.; Doval-Gandoy, J.; Rodas, J.; Benjelloun, K. Discrete sliding mode control based on exponential reaching law and time delay estimation for an asymmetrical six-phase induction machine drive. IET Electr. Power Appl. 2019, 13, 1660-1671. [CrossRef]

19. Utkin, V.; Guldner, J.; Shi, J. Sliding Mode Control in Electromechanical Systems; Taylor-Francis: Boca Raton, FL, USA, 1999.

20. Boiko, I.; Fridman, L. Analysis of Chattering in Continuous Sliding-mode Controllers. IEEE Trans. Autom. Control 2005, 50, 1442-1446. [CrossRef]

21. Ma, H.; Wu, J.; Xiong, Z. A Novel Exponential Reaching Law of Discrete-Time Sliding-Mode Control. IEEE Trans. Ind. Electron. 2017, 64, 3840-3850. [CrossRef]

22. Ma, H.; Li, Y.; Xiong, Z. Discrete-Time Sliding-Mode Control With Enhanced Power Reaching Law. IEEE Trans. Ind. Electron. 2019, 66, 4629-4638. [CrossRef]

23. Zhang, J.; Shi, P.; Xia, Y.; Yang, H. Discrete-Time Sliding Mode Control With Disturbance Rejection. IEEE Trans. Ind. Electron. 2019, 66, 7967-7975. [CrossRef]

24. Feng, Y.; Wen, X.; Xue, C.; Yu, X.; Han, F. Discrete-Time Quasi-Sliding Mode Control of Induction Motors. In Proceedings of the 2018 IEEE 8th Annual International Conference on CYBER Technology in Automation, Control, and Intelligent Systems (CYBER), Tianjin, China, 19-23 July 2018; pp. 1366-1369. [CrossRef]

25. Kali, Y.; Ayala, M.; Rodas, J.; Saad, M.; Doval-Gandoy, J.; Gregor, R.; Benjelloun, K. Time Delay Estimation Based Discrete-Time Super-Twisting Current Control for a Six-Phase Induction Motor. IEEE Trans. Power Electron. 2020, 35, 12570-12580. [CrossRef]

26. Harnefors, L.; Saarakkala, S.; Hinkkanen, M. Speed Control of Electrical Drives Using Classical Control Methods. IEEE Trans. Ind. Appl. 2013, 49, 889-898. [CrossRef]

27. Kali, Y.; Saad, M.; Benjelloun, K.; Fatemi, A. Discrete-time second order sliding mode with time delay control for uncertain robot manipulators. Robot. Auton. Syst. 2017, 94, 53 - 60. [CrossRef]

28. Poznyak, A.S. Chapter 12-Miscellaneous. In Advanced Mathematical Tools for Automatic Control Engineers: Deterministic Techniques; Poznyak, A.S., Ed.; Elsevier: Oxford, UK, 2008; pp. 213-227. [CrossRef]

29. Delorme, L.; Ayala, M.; Rodas, J.; Gregor, R.; Gonzalez, O.; Doval-Gandoy, J. Comparison of the Effects on Stator Currents Between Continuous Model and Discrete Model of the Three-phase Induction Motor in the Presence of Electrical Parameter Variations. In Proceedings of the 2020 IEEE International Conference on Industrial Technology (ICIT), Buenos Aires, Argentina, 26-28 February 2020; pp. 151-156. [CrossRef] 